\title{
Immune Mechanisms of Allergen-Specific Immunotherapy
}

\author{
Mona-Rita Yacoub ${ }^{1}$, Cristoforo Incorvaia, ${ }^{2, *}$, Marco Caminati $^{3}$ and Giselda Colombo ${ }^{1}$ \\ ${ }^{1}$ Allergy and Immunology Unit, San Raffaele Scientific Institute, Milan, Italy \\ ${ }^{2}$ Allergy/Pulmonary Rehabilitation, ICP Hospital, Milan, Italy \\ ${ }^{3}$ Allergy and Clinical Immunology School, University of Pavia - Allergy Unit, Fondazione Maugeri Scientific Institute, \\ Pavia, Italy
}

\begin{abstract}
Allergen immunotherapy (AIT) has the exclusive ability to modify the natural history of allergy and to maintain its clinical efficacy also after stopping the treatment. This occurs because of the AIT mechanism of action, mainly consisting in a specific induction of tolerance to the causative allergen. Such tolerance takes place as a result of a complex interaction of innate and adaptive immunity processes, that involve inflammatory cells, cytokines and chemokines. The first response to allergens is provided by the antigen-presenting cells, and particularly by dendritic cells (Dcs) that, following activation, acquire chemokine receptors (CCRs), useful for migration to lymphoid organs, where adaptive immune response is induced. DCs act by presenting the antigen(s) to effectors T cells (T helper CD4 + and T suppressor CD8 +) derived from naïve $\mathrm{T}$ cells. The development of different cell subtypes from naïve $\mathrm{T}$ cells $(\mathrm{Th} 0)$ may follow various pathways and depends on both individual genetic background (atopic/non atopic) and environmental factors. The $\mathrm{T}$ cell response in atopic subjects is influenced by the Th2 polarization promoting the production of cytokines such as IL-4 and IL5. On the contrary, the expression of CD80 may determine a Th1 cytokines production, and ICOS-L supports the Tregulatory cells activation that significantly reduce allergic inflammation. The suppressive effect of Treg is due to the expression of high level of the transcription factor Foxp3 on their surface, to the production of IL-10 and TGF- $\beta$ and to the expression of membrane molecules as CTL-4 PD-1 and BTLA. Recent advances highlighted a role also for Th9 and Th17 lymphocytes. Such immunologic modification leads to the long noted events in studies on mechanisms of action, such as the decrease of specific $\mathrm{IgE}$ and the increase of specific $\mathrm{IgG1}$ and $\mathrm{IgG} 4$, and ultimately on the inhibition of inflammatory cells such as mast cells, basophils and eosinophils and on the control of clinical symptoms.
\end{abstract}

Keywords: Allergen immunotherapy, mechanisms of action, tolerance, Th2 cells, T-regulatory cells, cytokines.

\section{INTRODUCTION}

One hundred years ago Noon reported the therapeutic efficacy of treatment with natural allergens for people suffering from respiratory allergy. He experienced inoculation of grass allergens extracts against hay fever and in 1911 he published the results of his study on the Lancet [1]. Many years passed before first "in vitro" experimental studies aimed to investigate allergen immunotherapy (AIT) mechanisms were conducted. In 1935 Cooke hypothesized the presence of allergen-specific soluble factors able to reduce allergic inflammation in the serum of patients treated with AIT [2]. No controlled clinical trials were carried out until the 1960s, thus the use of allergen extracts was somewhat empirical. Since the 1990s new acquisitions about pathophysiological aspects of allergic diseases and consequently about AIT mechanisms enabled to achieve the synthesis and modification of allergenic proteins in commercial extracts. This allowed advantages in safety and clinical efficacy of such extracts [3].

\footnotetext{
*Address correspondence to this author at the Allergy/Pulmonary Rehabilitation, ICP Hospital, via Bignami 120126 Milan, Italy; Tel: +390257993289; Fax: +390257993262; E-mail: cristoforo.incorvaia@gmail.com.
}

Nowadays, AIT represents the only curative treatment for respiratory allergic disease and insect venom hypersensitivity. It is able to interact with immune mechanisms of allergic inflammation, and to modify natural history of allergic diseases $[4,5]$. Moreover, AIT shows the opportunity of preventing the development of new sensitizations [6]. Induction of allergen-specific tolerance is a key event in successful outcome of AIT, obtained by purified allergen extracts. AIT interferes at various steps of immune response and its effects are enhanced by adjuvants and other molecules synthesized by means of genetic engineering techniques. Understanding how AIT works implies a comprehension of allergy pathogenetic background. The pattern of immune response, induced by exposure to an antigen, that is a potential allergen, depends on various factors, such as individual genetic background, environmental exposure and also antigen characteristics. The differences in the immune system response to low doses of allergen between healthy and atopic individuals are illustrated in Table $\mathbf{1}$.

The specific induction of tolerance to the causative allergen is the main mechanism of action of AIT. It is achieved by administering increasing and sufficiently high doses of an allergen extract via the subcutaneous or sublingual route [8]. This statement sounds simple, but it implies a complex interaction of innate and adaptive immunity processes, that in- 
Table 1. Immune response to Allergens in Healthy and Atopic Individuals*

\begin{tabular}{|c|c|c|}
\hline Immune Response to Low Doses of Allergen & Healthy & Atopic \\
\hline Humoral response & -Allergen specific $\operatorname{IgG} 1, \operatorname{IgG} 4$ and $\operatorname{Ig} A$ production & $\begin{array}{l}\text {-High amounts of specific IgE, and low amounts } \\
\text { of specific IgG 1, IgG4 and IgA }\end{array}$ \\
\hline
\end{tabular}

*Modified from Akdis CA, Akdis MA [7]

volve cells, cytokines and chemokines. As a result, both systemic allergic inflammation in patients with insect venom hypersensitivity and localized inflammation of respiratory tract, in patients with allergic rhinoconjunctivitis/asthma, are suppressed.

Here we summarize how AIT is active on the different phases and components of the immune response to allergens.

\section{ALLERGEN UPTAKE, PROCESSING AND PRESEN- TATION}

The first contact of an allergen with the immune system concerns the antigen presenting cells (APCs), particularly dendritic and epithelial cells of respiratory tract, that act as a first line defense against antigens and initiate the immune response. They express two kinds of molecules: 1) patternrecognition receptors (PRRs), a group of trans-membrane proteins able to recognize both common molecular structures detected on the membrane of pathogenic and nonpathogenic microorganisms (microorganism associated molecular patterns, MAMPs), and 2) antigenic molecules located on the surface of potential allergens. Among PRRs, Toll Like Receptors (TLRs) are the best characterized family members in mammals and humans [9].

MAMPs - PRRs linking can lead to the activation of several intracellular transcription factors, such as STAT-6 and GATA-3 in the context of Th2 immune response in atopic subject, or STAT-1 and T-bet in the context of Th1 immune response, in healthy subjects. This different pattern induction greatly depends on individual genetic background [10], and concurrent environmental conditions, resulting in a variety of immune response and clinical effects on target organs.

Dendritic Cells (DCs) form a complex network inside and below mucosal tissue of respiratory tract. In context of innate immune response, DCs are activated for their ability to recognize molecular structures expressed on the surface of antigens through their PRRs. Then, activated DCs lose their phagocytic capacity and acquire chemokine receptors (CCRs), useful for migration to lymphoid organs, where adaptive immune response is induced. DCs act as an APC, considering their ability to expose antigen-derived peptides in the context of class II MCH molecules, in order to present them to T cells [11]. They are the only type of class II MCHexpressing APCs that can efficiently activate and polarize naïve Th cells (Th0). DCs exert the same function in the con- text of adaptive immune response by presenting antigens to effectors T cells ( $\mathrm{T}$ helper CD4 + and T suppressor CD8 +) derived from naïve T cells [12]. DCs are particularly located in mucosal tissue of respiratory tract as sentinel cells. In this context, they regulate the development of Th1, Th2 and Tregulatory cells, and contribute to maintain a state of immunologic tolerance in the airways [12]. In allergic patients a greater amount of DCs has been detected in nasal and bronchial mucosal tissue after specific challenge with allergens, namely house dust mites, HDM [13]. DCs express CCR7 that polarizes a Th2 immune response $[12,13]$. CCR3, CCR4, CCR8 are other chemokines involved in type 2 pattern of response. Usually allergens are not immunogenic antigens. In order to activate DCs and induce sensitization, they need co-stimulatory "danger" signals, such as environmental viral or bacterial-derived compounds, enzymes or other allergen-derived molecules (i.e. proteases from HDM).

Recently, therapeutic manipulation of PRRs aroused great interest in the field of AIT. This approach aims to create more effective vaccines able to balance the immune response by polarizing a Th1 shift [14]. Recombinant DNA technology enabled the characterization of genes codifying for single allergenic peptides and consequently the creation of amino acid sequences, that exactly reproduce native allergenic epitopes. On the basis of c-DNA sequences, dimeric and trimeric oligonucleotides codifying for allergens and epitopes shared by different allergens have been synthesized. Also conjugation to bacterial DNA sequences, called $\mathrm{CpG}$ immunostimulatory oligonucleotides, enables those molecules to bind TLR4, becoming adjuvants in promoting a switch from Th2 to Th1 immune response. In a pilot study, subcutaneous IT (SCIT) composed by ragweed-pollen major allergen Amb a 1 conjugated to a sequence of DNA with a $\mathrm{CpG}$ motif has been investigated in patients suffering from allergic rhinitis [15]. The immunostimolatory sequence binds to TLR 9 and this interaction is associated with an inhibition of Th2 mediated immune response and subsequently of allergic tissue inflammation, with a resulting good clinical outcome $[15,16]$. Treatment with a similar synthetic oligonucleotide administered by inhalation has shown the ability to modulate expression of Th1 cytokines genes, but failed to improve respiratory function in asthmatic subjects in response to allergen inhalation challenge [17]. Also traditional allergenic extracts conjugated to monophosphoryl lipid (MPL)-A as an adjuvant binding to TLR 4, significantly re- 
duced global symptom score in allergic patients. MPL adjuvated IT is already available in routine setting by SCIT [18]. Further studies are needed in order to evaluate the use of recombinant allergens, produced by DNA technology. At the moment it represents the new frontier of AIT, particularly concerning inhalant allergens, because it allows highly specific treatment for patients according to their sensitization profile. High and repeated doses of recombinant allergens, through antigen processing provided by APCs are able to inactivate CD4+ lymphocytes, resulting in effective treatment of allergy $[19,20]$. A fusion protein composed of major allergen and adjuvant molecules that bind to TLR can be produced by genetic engineering. In this context bee venom has provided an interesting model to study new tools for vaccines innovation. Phospholipase A2, the major allergen of bee venom, can be conjugated to hyaluronidase in order to obtain a novel more effective fusion protein able to reduce allergic response [21]. Bacterial derived proteins binding TLR2, such as lipoproteins from Gram negative capsule, can exert a similar function, polarizing immune response toward Th1 pattern.

It is therefore clear - as confirmed by several studies conducted on animal models and in humans - that APCs, particularly DCs, have a pivotal role in the induction of functional activity of $\mathrm{T}$ cells and their differentiation in various phenotypes. The development of different cell subtypes from naïve $\mathrm{T}$ cells (Th0) may follow various pathways and depends on both individual genetic background (atopic/non atopic) and environmental factors. DCs are essential in orchestrating the immune response through signals that result from MAMP-PRR linking. The first step of specific immunity, initiated by DCs, is the production of cytokines (IL-12, IL-10 and IFN- $\gamma$ ) promoting T regulatory cells activation and Th1 pattern of response. In allergic subjects APCs determine the production of Th2 phenotype cytokines [22].

\section{THE T CELL RESPONSE}

Together with DCs, several factors are implicated in the regulation of naive $\mathrm{T}$-cell differentiation into $\mathrm{Th} 1$ or $\mathrm{Th} 2$ effectors, including the amount of antigen, the duration of antigen presentation, the strenght and nature ot interaction between T cells and APCs and the cytokine milieu in which $\mathrm{T}$ cells are primed. Costimulatory molecules (CD86, OX40) expressed by APCs (epithelial cells of respiratory tract and DCs) during antigen presentation and their ligands on LT surface seem to have a pivotal role in provoking allergic inflammation. In fact in atopic subjects they favor Th2 polarization of immune response by promoting production of Th2 cytokines such as IL4 and IL5 [23, 24]. On the contrary, the expression of CD80 may determine a Th1 cytokines production and ICOS-L supports T-regulatory cells activation and influences the production of cytokines (IL10, TGF B) that significantly reduce allergic inflammation [25].

According to preliminary studies, recently conducted on animal models, AIT seems to prevent the development of new allergic disease onset. Preliminary results show in fact its ability to directly influence DCs activity and modulate expression of costimulatory molecules, particularly ICOS-L, on their surface [25]. After activation and differentiation processes, $\mathrm{T}$ naïve cells become effectors $\mathrm{T}$ cells, that migrate from lymph nodes to mucosal tissue of respiratory tract and produce pro-inflammatory cytokines. Chemokines receptors, expressed on the cells involved in inflammatory process, enable their recruitment and circulation. In fact, secretion of the ligands for those receptors can drive allergen-specific $\mathrm{T}$ cells in different tissues. Moreover, adhesion molecules allow immune cells to bind to the vascular endothelium and to "home" to sites of tissue inflammation. Chemical signals are responsible for "homing mechanisms" that orient cells migration to alveolar or bronchial tissue and provide inflammation maintenance.

There are five main functional subtypes of $\mathrm{T}$ helper CD4+, distinguished by their cytokine profile. Other minor T cell subsets do not have a direct role. However, the plasticity of these cells allowed them to shift from a type to another, depending of APCs signalling, that depend in turn of the linkage between antigen and TLR [26]:

Th-1 lymphocytes: mature from naïve cells (Th0) thanks to both presence of IL-12 (produced by DCs) in the microenvironment and activation of STAT1 and T-bet transcription factors. Th1 produce IFN- $\gamma$. Under physiological conditions, they are active in the defence against intracellular pathogens, by means of their collaboration with B lymphocytes, that, after their transformation in plasma cells, synthesize protective antibodies (in humans $\operatorname{IgM}, \operatorname{IgA}, \operatorname{IgG} 1, \operatorname{IgG} 2$, IgG3); under pathological conditions, if they are overactivated, they promote autoimmune diseases.

Th-2 lymphocytes: mature from naïve cells (Th0), that, under IL-4 stimulation, activate transcription factors STAT-6 and GATA-3. They produce a big range of cytokines, included IL-4, IL-5 and IL-13. Th-2 lymphocytes are the main Th population in atopic patients $[27,28]$. IL-4, IL-5 and IL-13 chime both in early and late phase of allergen specific immune response. IL-4 promotes isotopic switch that leads B cells to produce specific IgE. IL-5 promotes eosinophils activation, differentiation and survival. IL13 promote IgE production. The link between IgE and FceR1, located on basophils and mast cells membrane induce their degranulation with subsequent release of pre-formed and newly formed mediators, included cytokines (IL4, IL-5, IL 13, TNF- $\alpha$, eotaxin) and chemokines, that induce the expression of adhesion molecules on endothelial cells and to the recall of eosinophils and other cells in inflamed tissue.

Th-9 lymphocytes: mature from Th2 cells, under the influence of IL4 and TGF- $\beta$. They produce IL-9, that promote the proliferation of eosinophils, basophils and mast cells, also by means of an up-regulation of high affinity receptor for IgE (FceRI) located on their surface. They play a role in the maintenance of inflammation, stimulate globet cells to produce mucus and participate to airways remodelling process [29].

Th-17 lymphocytes: mature from naïve cells (Th0). They produce IL-17 and are principally involved in the pathogenesis of autoimmune and chronic granulomatous diseases. In humans, plasticity of these cells allows them a shift from Th-17, IL-17 producers, to Th-2, IL-4 producers [30]. In asthma, IL-17 produc- 
tion characterize neutrophils phenotype, while IL-4 production characterize eosinophils phenotype. These different phenotypical expression are linked to a different genotype background [31]

T regulatory lymphocytes (Treg): they are suppressive cells, that generate during adaptive response to exogenous antigens. Two subpopulations of Treg are well-characterized: 1) naturally occurring Treg cells evolving in the thymus CD4+CD25+ is characterized by constitutive expression of forkhead winged-helix transcriptional factor Foxp3), that seems negatively correlates with CD127 expression $[32,33]$; 2) inducible type 1 Treg $(\operatorname{Tr} 1)$ cells, generated outside the thymus are characterized by the secretion of IL-10. The suppressive effect of Treg is due to the expression of high level of the transcription factor Foxp3 on their surface, to the production of Il-10 and TGF- 3 and to the expression of membrane molecules as CTL-4 PD-1 and BTLA [33]. CD4+CD25+ Treg are able to suppress the above mentioned effectors $\mathrm{T}$ cells subtypes, either directly, or through important effects on DCs: a) they form aggregates around CDs, by means of the adhesion molecule LFA1, to impede exposure of co-stimulatory molecules CD80 and CD86 on CDs [12]; b) they compete with naïve $\mathrm{T}$ cells (Th0) for their contact with DCs, reducing their capacity to activate effectors $\mathrm{T}$ cells; c) they suppress mast cells, basophils and eosinophils that infiltrate inflamed organs, leading to "remodelling"; d) they directly interact with neutrophils, $B$ and $T$ cells and natural killer cells by means of cytokine and soluble factors, that lead to microenvironment variation [7].

The shift from Th2 cells, that characterize the atopic background, to the protective Th1 phenotype, induced by the administration of repeated high dose of allergen, as occurs by AIT, is principally due to Treg induction and IL-10 production. Thanks to multiple interactions between Treg and the other cells of immune system, a conversion into a specific tolerance state toward the implied allergen is obtained [34] In this way, AIT effects are relevant either on humoral or on cell-mediated response toward the specific allergen [35]. As reported above, AIT effects on the humoral response, namely on the increase of IgG1 and $\mathrm{IgG} 4$ and, in a less extent of allergen-specific IgA, are well-known. The mechanisms that explain these modifications have instead been discovered more recently. We know nowadays that B cell activation that leads to the production of "blocking" IgG4 antibodies is favoured by IL-10 effect [36]. Similarly, also "protective" IgA are synthesized for the effect of IL-10 and TGF $\beta$ [37-39]. These antibodies, found in nasal lavage and in serum of patients treated with AIT, are able to inhibit histamine release from basophils, for their capacity to compete with specific IgE for the link with Fc-eRI receptors, expressed on basophils surface. Moreover, IgG produced after AIT may hinder mucosal presentation of the complex allergen-IgE to APCs, as shown in in vitro model using serum of birch pollen allergic patients [40]. This inhibitory activity has been confirmed in various studies, mainly conducted on patients treated with SCIT. These studies underline the relevance of IgG4 to suppress, by mean of Treg $\mathrm{CD} 4+\mathrm{CD} 25+$, the activation of $\mathrm{Th} 2$ and $\mathrm{B}$ cells that produce specific IgE, either in patients with respiratory allergy or in those with hymenoptera venom allergy $[41,42]$. To illustrate the AIT ability to stimulate Treg activation, a significant increase of Treg cell CD4+CD25+ has been demonstrated in nasal mucosa and peripheral blood of subjects treated with grass pollen AIT. The same study underlined that during the pollination season, the clinical efficacy of AIT treatment and the inhibition of target-organ inflammation are directly proportional to Treg nasal concentration at the end of SIT [43]. AIT also activates IL-10 codifying mRNA, not only in Treg but also in B cells, monocytes and DCs that act as APCs. IL10 suppresses either total IgE production either allergenspecific IgE, and this enhances its anti-inflammatory effect. It is also able to induce a switch from $\operatorname{IgE}$ to $\operatorname{IgG}$, acting on allergen specific B cells, that synthesize IgG1 and IgG4. The increase in allergen specific IgG4 is more pronounced than IgG1. A main characteristic of these antibodies is that their heavy chain can change, transforming them into monomeric antibodies with a low affinity with Fc $\gamma$ receptor, that is able to link to allergens but not to mast cells. In this way either IgE-mediated mast cells activation, either preformed and newly formed cytokines liberation are inhibited and therefore early and late allergic inflammation are suppressed. For these reasons these IgG can be called "blocking antibodies". AIT is also able to inhibit IL-5 production and to promote eosinophils apoptosis [7]. These effects are also proven by a significant reduction of inflammatory infiltrate, composed by $\mathrm{T}$ and B lymphocytes, eosinophils, basophils, mast cells and neutrophils, and also of cytokines in nasal biopsies, performed during and outside pollination season, in subjects treated with SIT compared with untreated subjects [44]. Similarly, AIT may also promote TGF- $\beta$ synthesis, a potent immunoregulatory cytokine, that is essential for the maintenance of self tolerance. TGF- $\beta$ is also able to induce Treg Foxp3+ proliferation, to down regulate high affinity receptor for $\operatorname{IgE}(\mathrm{Fc}-\varepsilon-\mathrm{RI})$ expression on DCs and to suppress $\operatorname{IgE}$ synthesis and promote $\operatorname{IgA}$ synthesis [35]. Thanks to the regulatory role of TGF- $\beta$ and IL10, AIT with a sublingual extract of HDM induced was shown to induce a significant decrease of $\operatorname{IgE}$ and a simultaneous increase of $\operatorname{IgA}$ in children suffering from allergic asthma [45]. Regarding the concentration of blocking antibodies IgG4 and the long-term efficacy of AIT, there are discordant opinions. In fact, some authors observed that despite a $80 \%$ IgG4 reduction two years after stopping the treatment, clinical efficacy persisted. These authors therefore assumed a functional role rather than a quantitative role of IgG4 to contribute to the long-term efficacy of SIT [46]. Instead, in a recent multicentric study, results obtained after a 3 -years treatment with a grass pollen sublingual extract in patients suffering from moderate to severe allergic rhinocongiuntivitis showed a significant difference in IgG4 and other "blocking" factors (able to link allergen competing with IgE) in favour of treated vs. untreated subjects, already after two months of treatment. Two years after ending AIT, a significant difference between the two groups was maintained regarding both IgG4 concentration $(\mathrm{P}<.0001)$, and IgE blocking factors $(\mathrm{p}<.0001)$ [47].

AIT effects on $\mathrm{B}$ cells, consisting in the induction of a shift in allergen specific IgE production to specific IgG4 is not a "all-or-nothing effect". As a matter of fact, IgE synthesis is not immediately inhibited after AIT beginning, and that 
explains the increased level of either specific $\operatorname{IgE}$ and even more of specific IgG4 during the first months after the beginning of the treatment, when an early desensitization effect already occurs [48]. The ratio of specific IgE/specific IgG4 decreases since six months to three years after beginning of AIT. Moreover, in patients suffering from pollen respiratory allergy, during the pollination season, AIT inhibit the expected $\operatorname{IgE}$ increase. These variations of allergen specific humoral response are equally obtained with subcutaneous and sublingual extracts [49-51]. A recent study on a cohort of patients suffering from asthma and/or rhinoconjunctivitis due to sensitization to ragweed pollen treated with SLIT, demonstrated that this treatment is able to act on the different phases of the immune response: 1) by reducing the expression of costimulatory CD80 and CD86, not only on APCs but also on monocytes and B lymphocytes; 2) by downregulating APC functions through an increase of the expression of programmed cell death ligand (PD-L1), that leads to IL-10 production; 3) by inducing IL-10 production by Treg cells, whereas it inhibits IL-4 producing cells; 4) by inducing a significant $\mathrm{IgG} 4$ increase [52]. All these markers were measured twice in and out of the pollination period and were correlated with clinical efficacy, by analyzing visual analogic scale score and drug consumption. The authors concluded that clinical efficacy of SLIT is associated with modulation of PD-L1, IL-10 and IgG4, and that PD-L1 expression is the best marker of clinical efficacy of SLIT. In particular, the switch to IL-10 secreting Treg is driven by exposure to high allergen doses [53]. The final event of the sequence started by the contact with the causative allergen is the release of mediators by the effector cells, such as mast cells, basophils, and eosinophils, that in turn is responsible of the effects on target organs and therefore on the occurrence of clinical symptoms. The outcome of AIT on effectors cells is long known [54], but now we know that the most potent controller of the activity of effector cells are Tregs [55], and in particular that basophils, thus far considered less essential than mast cells and eosinophils, show different pathways of modulation associated with the different forms of AIT and have a potential use as a biomarker of clinical outcome of the treatment [56].

\section{CONCLUSIONS}

The recent research on AIT, in its subcutaneous and sublingual forms, has confirmed the ability of this treatment to modify the natural history of allergy and to maintain its clinical efficacy also after stopping. This occurs because of the AIT mechanisms of action, mainly consisting in a specific induction of tolerance to the implicated allergen, that has central importance in preventing the IgE-mediated reaction and the consequent inflammation characterizing the allergic disease. Such tolerance results from a first response to allergens provided by the antigen-presenting cells, and particularly by dendritic cells (Dcs) that, following activation, act by presenting the allergen to T cells ( $\mathrm{T}$ helper $\mathrm{CD} 4+$ and $\mathrm{T}$ suppressor $\mathrm{CD} 8+$ ) derived from naïve $\mathrm{T}$ cells. The $\mathrm{T}$ cell response in atopic subjects is influenced by the Th2 polarization promoting the production of cytokines such as IL-4 and IL-5. Instead, the expression of CD80 may determine a Th1 cytokines production, and the T-regulatory cells activation significantly reduce allergic inflammation. The suppressive effect of Treg is due to the expression of high level of the transcription factor Foxp3 on their surface, to the production of IL-10 and TGF- $\beta$ and to the expression of membrane molecules as CTL-4 PD-1 and BTLA. Recent advances highlighted a role also for Th9 and Th17 lymphocytes. Such immunologic modification leads to the well known, but long not well understood, phenomena of the decrease of specific $\mathrm{IgE}$ and increase of specific IgG1 and $\mathrm{IgG} 4$, and ultimately on the inhibition of inflammatory cells such as mast cells, basophils and eosinophils which is mirrored by the control of clinical symptoms.

\section{CONFLICT OF INTEREST}

The author confirms that this article content has no conflicts of interest.

\section{ACKNOWLEDGEMENT}

Declared none.

\section{REFERENCES}

[1] Noon L. Prophylactic inoculation against hay fever. Lancet 1911; 177: 1572-3.

[2] Cooke RA, Barnard JH, Hebald S, Stul A. Serological evidence of immunity with coexisting sensitization in a type of human allergy (hay fever). J Exp Med 1935; 62: 733-50.

[3] Bousquet J, Lockey R, Malling HJ. WHO panel members. Allergen immunotherapy: therapeutic vaccines for allergic diseases: a WHO position paper. J Allergy Clin Immunol 1998; 102: 558-62.

[4] Durham SR, Walker SM, Varga EM, et al. Long-term clinical efficacy of grass-pollen immunotherapy. N Engl J Med 1999; 341: 468-75.

[5] Jacobsen L, Niggemann B, Moller C, et al. Specific immunotherapy has long-term preventive effects of seasonal and perennial asthma: 10-year follow-up on PAT study. Allergy 2007; 62: 943-8.

[6] Paino GB, Barberio G, De Luca F, Morabito L, Parmiani S. Prevention of new sensitizations in asthmatic children monosensitized to house dust mite by specific immunotherapy. A six year followup study. Clin Exp Allergy 2001; 31: 1932-7.

[7] Akdis CA, Akdis MA. Mechanisms and treatment of allergic disease in the big picture of regulatory T cells. J Allergy Clin Immunol 2009; 123: 735-46.

[8] Incorvaia C, Frati F. One century of allergen-specific immunotherapy for respiratory allergy. Immunotherapy 2011; 3: 629-35.

[9] Kaisho T, Akira S. Toll-like receptor function and signalling. J Allergy Clin Immunol 2006; 117: 979-87.

[10] Vercelli D. Learning from discrepancies: CD14 polymorphism, atopy and the endotoxin switch. Clin Exp Allergy 2003; 33: 153-5.

[11] Tsicopoulos A, Azzaoui I, Duez C. Immunité innée et allergie: les cellules dendritiques. Innate immunity and allergy: the dendritic cells. Rev Fr Allergol 2008; 48: 150-4.

[12] Burchell JT. The role of dendritic cells and regulatory T cells in allergic asthma. Pharmacol Ther 2010; 125(1): 1-10.

[13] Hammad H, Lambrecht BN, Pochard P, et al. Monocyte-derived dendritic cells induce a house dust mite-specific Th2 allergic inflammation in the lung of humanized SCID mice: involvement of CCR7. J Immunol 2002; 169: 1524-34.

[14] Kanzler H. Therapeutic targeting of innate immunity with toll-like receptor agonists and antagonists. Nat Med 2007; 13: 552-9.

[15] Tulic MK, Fiset PO, Christodoulopoulos P, et al. Amb a 1immunostimulatory oligodeoxynucleotide conjugate immunotherapy decreases the nasal inflammatory response. J Allergy Clin Immunol 2004; 113: 235-4.

[16] Creticos PS, Schroeder JT, Hamilton RG, et al. Immunotherapy with a ragweed-toll-like receptor 9 agonist vaccine for allergic rhinitis. N Engl J Med 2006; 355: 1445-55.

[17] Gavreau GM, Hessel EM, Boulet LP, Coffman RL, O'Byrne PM. Immunostimulatory sequences regulate interferon-inducible genes but not allergic airway responses. Am J Respir Crit Care Med 2006; 174: 15-20.

[18] Mc Cormack PL, Wagstaff AJ. Ultra-short-course seasonal allergy vaccine (Pollinex Quattro). Drugs 2006; 66: 931-8. 
[19] Jutel M, Jaeger I, Suck R, Meyer H, Fiebig H, Cromwell O. Allergen immunotherapy with recombinant grass allergens. J Allergy Clin Immunol 2005; 116: 608-13.

[20] Pauli G, Larsen TH, Rak S, et al. Efficacy of recombinant birch pollen vaccine for the treatment of birch-allergic rhinoconjunctivitis. J Allergy Clin Immunol 2008; 122: 951-60.

[21] Kussebi F, Karamloo F, Rhyner C, et al. A major allergen genefusion protein for potential usage in allergen-specific immunotherapy. J Allergy Clin Immunol 2005; 115: 323-9.

[22] Allam JP, Novak N, Fuchs C, et al. Characterization of dendritic cells from human oral mucosa: a new Langerhans cell type with high constitutive FcepsilonRI expression. J Allergy Clin Immunol 2003; 112: 141-8.

[23] Ohshima Y, Yang LP, Uchiyama T, Tanaka Y, Baum P, Sergerie M. OX40 costimulation enhances interleukin-4 (IL-4) expression at priming and promotes the differentiation of naïve human CD4+ Tcells into high IL-4 producing effectors. Blood 1998; 92: 333845.

[24] Beier KC, Kallinich T, Hamelman E. T-cell co-stimulatory molecules: novel targets for treatment of allergic airway diseases. Eur Respir J 2007; 30: 383-90.

[25] Ito T, Yang M, Wang YH, Lande R, Gregorio J, Perng OA. Plasmocytoid dendritic cells prime IL-producing $\mathrm{T}$ regulatory cells by inducible costimulator ligand. J Exp Med 2007; 204: 105-15.

[26] Annunziato F, Romagnani S. Heterogeneity of human effector CD4 T cells. Arthritis Res Ther 2009; 11: 257.

[27] Gould HJ, Sutton BJ, Beavil RL, et al. The biology of IgE and the basis of allergic diseases. Annu Rev Immunol 2003; 21: 579-628.

[28] Chatila TA, Li N, Garcia Lloret M, Kim HJ, Nel AE. T-cell effector patways in allergic diseases: trascriptional mechanisms and therapeutic targets. J Allergy Clin Immunol 2008; 121: 812-25.

[29] James LK, Durham SR. Update on mechanism of allergen injection immunotherapy. Clin Exp Allergy 2008; 38: 1074-88.

[30] Annunziato F, Romagnani S. Do studies in humans better depicts Th17 cells? Blood 2009; 114: 11.

[31] Cookson W. Genetics and genomics of asthma and allergic diseases. Immunol Rev 2002; 190: 195-206.

[32] Möbs C, Slotosch C, Löffler H, Jakob T, Hertl M, Pfützner W. Birch pollen immunotherapy leads to differential induction of regulatory $\mathrm{T}$ cells and delayed helper $\mathrm{T}$ cell immune deviation. J Immunol 2010; 184: 2194-203.

[33] Weihong L, Putnam A, Zhou Xu-Yu, et al. CD127 expression inversely correlates with FoxP3 and suppressive function of human CD4+ T reg cells. J Exp Med 2006; 203: 1701-11.

[34] Veldhoen M, Uyttenhove C, van Snick J, Helmby H, Westendorf A, Buer J. Trasforming grow factor-beta reprograms the differentiation of $\mathrm{T}$ helper 2 cells and promotes an interleukin producing subset. Nat Immunol 2008; 9: 1341-6.

[35] Burastero SE, Mistrello G, Falagiani P, Paolucci C, Breda D, Roncarolo D. Effect of sublingual immunotherapy with grass monomeric allergoid on allergen specific T-cell proliferation and interleukin-10 production. Ann Allergy Asthma Immunol 2008; 100(4): 343-50.

[36] Till SJ, Francis JN, Nouri-Aria K, Durham SR. Mechanisms of immunotherapy. J Allergy Clin Immunol 2004; 113: 1025-34.

[37] Thunberg S, Akdis M, Akdis CA, et al. Immune regulation by CD4+CD25+ T cells and interleukin-10 in birch pollen-allergic patients and non-allergic controls. Clin Exp Allergy 2007; 37: 112736.

[38] Jutel M, Adkis M, Budak F, et al. IL-10 and TGF-beta cooperate in the regulatory $\mathrm{T}$ cell response to mucosal allergens in normal immunity and specific immunotherapy. Eur J Immunol 2003; 33: 1205-14.
[39] Nouri-Aria KT, Wacholz PA, Francis JN, Jacobson MR, Walker SM, Wicock LK. Grass pollen immunotherapy induces mucosal and peripheral IL-10 response and blocking IgG activity. J Immunol 2004; 172: 3252-9.

[40] Pilette C, Nouri Aria KT, Jacobsen MR, et al. Grass pollen immunotherapy induces an allergen specific IgA2 antibody response associated with mucosal TGF-beta espression. J Immunol 2007; 178: 4658-66.

[41] Ejrnaes AM, Svenson M, Lund G, Larsen JN, Jacobi H. Inhibition of rBet v1- induced basophils histamine release with specific immunotherapy-induced serum immunoglobulin G: non evidence that FcgammaRIIB signalling is important. Clin Exp Allergy 2006; 36: 273-82.

[42] Gehlhar K, Schlaak M, Becker W, Bufe A. Monitoring allergen immunotherapy of pollen-allergic patients: the ratio of allergen specific IgG4 to IgG1 correlates with clinical outcome. Clin Exp Allergy 1999; 29: 497-506.

[43] Ewan PW, Deighton J, Wilson AB, Lachman PJ. Venom-specific IgG antibodies in bee and wasp allergy: lack of correlation with protection from stings. Clin Exp Allergy 1993; 8: 647-60.

[44] Radulovic S, Jacobson MR, Durham SR, Nouri Aria KT. Grass pollen immunotherapy induces Foxp3 expressing CD4+CD25+ cells in the nasal mucosa. J Allergy Clin Immunol 2008; 121: 146772 .

[45] Iliopulos O, Proud D, Adkinson NF Jr. Effects of immunotherapy on the early, late and rechallenge nasal reaction to provocation with allergen:changes in inflammatory mediators and cells. J Allergy Clin Immunol 1991; 87: 855-66.

[46] Bahceciler NN, Arikan C, Taylor A, Akdis M, Barlan IB. Impact of sublingual immunotherapy on specific antibody levels in asthmatic children allergic to house dust mites. Int Arch Allergy Immunol 2005; 136: 287-94.

[47] Wilcock LK, Wacholz PA, Na DH. Time course of serum IgG4 levels and IgG inhibitory activity following withdrawal of grass pollen immunotherapy. J Allergy Clin Immunol 2005; 115: S265.

[48] Horak F, Zieglmayer P, Zieglmayer R, Lemell P, Deviller P, Montagut A. Early onset of action of a 5-grass pollen 300-IR sublingual immunotherapy tablet evaluated in an allergen challenge chamber. J Allergy Clin Immunol 2009; 124: 471-7.

[49] Moingeon P, Batard T, Fadel R, Frati F, Sicher J, Van Overtvelt L. Immune mechanisms of allergen specific sublingual immunotherapy. Allergy 2006; 61:151-65.

[50] Fujita H, Soyka MB, Akdis M, Akdis CA. Mechanisms of allergenspecific immunotherapy. Clin Transl Allergy 2012; 5: 2.

[51] Rossi RE, Monasterolo G, Coco G, Silvestro L, Operti D. Evaluation of serum IgG4 antibodies specific to grass pollen allergen components in the follow up of allergic patients undergoing subcutaneous and sublingual immunotherapy. Vaccine 2007; 25: 957-64.

[52] Picone S, Trabattoni D, Rainone V, et al. Immunological effects of sublingual immunotherapy: clinical efficacy is associated with modulation of programmed cell death ligand 1, IL-10 and IgG4. J Immunol 2010; 185: 7723-30.

[53] Meiler F, Zurnkehr J, Klunker S, Ruckert B, Akdis CA, Akdis M. In vivo switch to Il-10 secreting T regulatory cells in high dose allergen exposure. J Exp Med 2008; 205: 2887-98.

[54] Rak S, Hakanson L, Venge P. Immunotherapy abrogates the generation of eosinophil and neutrophil chemotactic activity during pollen season. J Allergy Clin Immunol 1990; 86: 706-13.

[55] Ozdemir C, Kukuzsezer UC, Akdis M, Akdis CA. Specific immunotherapy and turning off the T cell: how does it work? Ann Allergy Asthma Immunol 2011; 107: 381-92.

[56] Patil SU, Shreffler WG. Immunology in the clinic review series; focus on allergies: basophils as biomarkers for assessing immune modulation. Clin Exp Immunol 2012; 167: 59-66.

Received: June 16, $2011 \quad$ Revised: July 15, 2012

Accepted: July 21, 2012

(C) Yacoub et al.; Licensee Bentham Open.

This is an open access article licensed under the terms of the Creative Commons Attribution Non-Commercial License (http://creativecommons.org/licenses/by-nc/3.0/) which permits unrestricted, non-commercial use, distribution and reproduction in any medium, provided the work is properly cited. 